\title{
Eco Sustainable Rail - Valorization of Mixed Plastics in the Development of Eco-Sustainable Railways
}

\author{
Joana Carvalho ${ }^{1,2^{*}}$, André Mota ${ }^{1}$, André Ribeiro ${ }^{1}$, Margarida Soares ${ }^{1}$, \\ Jorge Araújo ${ }^{1}$, Cândida Vilarinho ${ }^{2}$
}

\begin{abstract}
:
The mixed plastics, by their heterogeneity and contamination characteristics, constitute the extreme situation of difficulty in recycling, which has greatly contributed to a high fraction of mixed plastics landfilled. This situation is a cause for concern, and it is imperative to search for new application solutions for these wastes and its valorization as a raw material of high value-added products. Currently exists in Portugal and globally a need to find solutions for railway sleepers, to be a viable alternative to the replacement of wood railway sleepers, which usually have a special application and cannot be replaced by cement solutions existing on the market. Thus, the ECO SUSTAINABLE RAIL project intends to meet the listed requirements, through the mixed plastics valorization in the development of the eco-sustainable sleepers, mostly made of mixed plastics, to be tested in real scenario of operation in Infrastructures of Portugal. The ECO SUSTAINABLE RAIL project will be supported in the development of three research lines (research and development of a new material mostly of mixed plastics, research of a sleeper geometry, research of a new production process), the development of life-cycle analysis and environmental assessment of the sleepers real scenario and the sleepers testing in real operating condition. For the project execution, it was established a set of entities consortium, with experience and complementary skills, including the leading EXTRUPLÁS company, the Innovation Pole in Polymer Engineering (PIEP) and the Centre for Waste Valorization (CVR), that with the technical support of Infrastructures of Portugal (IP) will be able to develop and test a new railway sleeper of quality and with less environmental impact. Overall the project ECO SUSTAINABLE RAIL will contribute to reduce the deposition of mixed plastic in landfills, to respond to a need of the railway sector, and to allow the expansion and differentiation of the EXTRUPLÁS products portfolio, which will strengthen its position in the plastic recycling sector.
\end{abstract}

Keywords: Mixed plastics, V alorization, Eco-sustainable railways

\section{Introduction}

The ECO SUSTAINABLE RAIL Project aims to enhance the use of mixed plastics in the development of eco-sustainable railway sleepers, which will be tested in a real working environment. It will contribute strongly to the promotion of the recycling of mixed plastics, with the incorporation of technology, transforming them into valueadded products with potential to the market.

\footnotetext{
$\mid{ }^{1}$ CVR- Centro para Valorização de Resíduos

*Corresponding author: jcarvalho@cvresiduos.pt
} 


\section{Mixed Plastics - Recycling Problems}

In the last six and a half decades, thanks to its exceptional properties (great versatility, easy processability, low cost, low specific weight, adequate combination of physical and chemical characteristics, among others), plastic materials had an explosive growth in terms of production and consumption, becoming the most ubiquitous materials in this century, even surpassing (by volume) the ferrous materials.

In fact, the properties of these materials make them particularly suitable for use in applications of high ubiquity and rapid obsolescence, such as packaging, namely food, which, together with high portability (consequence of low specific weight, versatility and easy processing), resistance to environmental degradation and the perception of reduced intrinsic value, make them dominant materials in municipal solid waste (MSW) and in the environment.

It is estimated (it is difficult to consolidate accurately all the data) that in 2013, worldwide, 78 million tons of plastic materials in packaging were used, of which, in the End of Life (EoL), 11 million (14\%) were energetically valorized and about 8 million recycled $(20 \%$ of these in products with the same level of specifications - closed loop recycling). The remainder was either landfilled and was lost to the recycling process (since all recycling facilities have incomes of less than $100 \%$, up to $50 \%$ in the case of heavily contaminated post-consumer plastics) or have been abandoned irresponsibly in the environment. On the other hand, considering all the applications of plastics and the countries of the European Union, in addition to the obvious reduction of scale (59 million tons were produced in 2014 and 26 million tons of waste generated), the situation of plastic materials is not qualitatively different from the world, as can be seen in Figure 1.

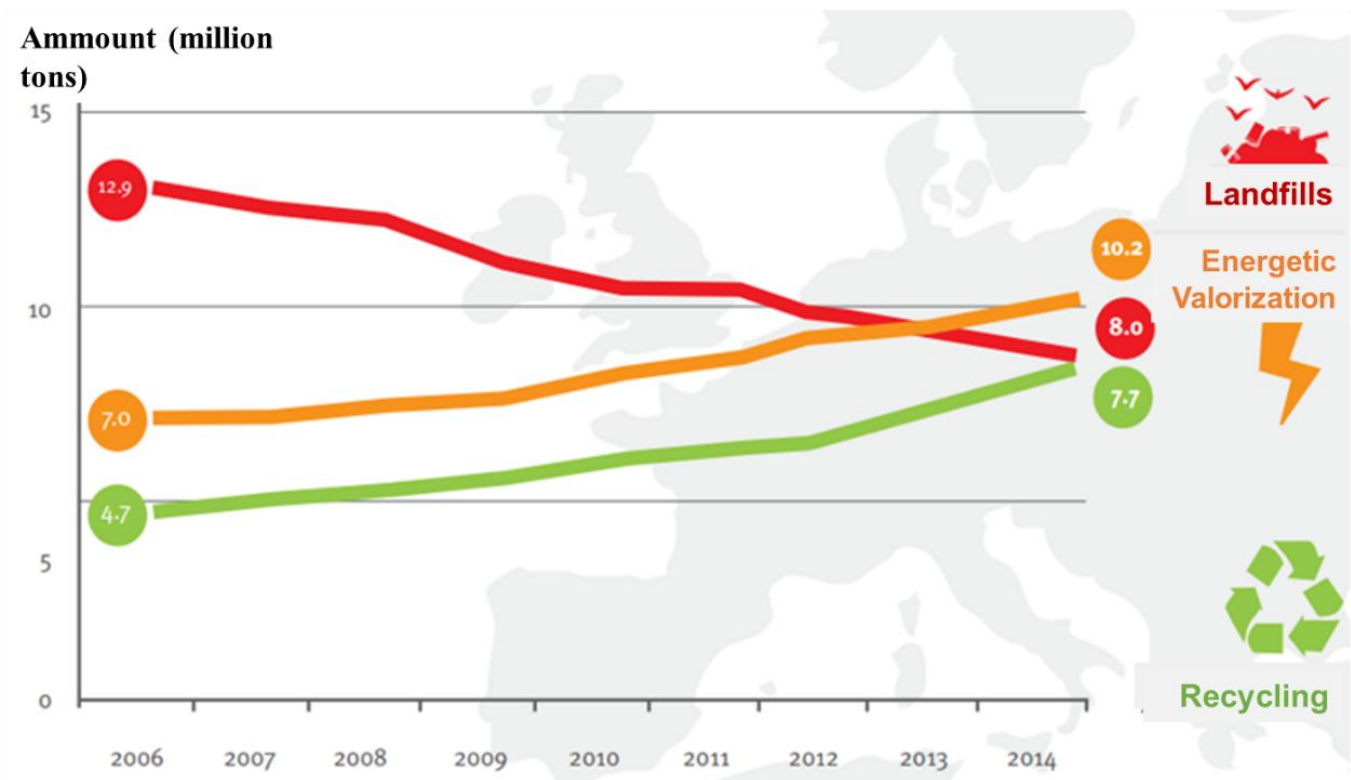

Figure 1. 2006 to 2014 evolution of end-of-life treatments (EoL) of plastic materials in the EU28 [1] 
However, in the European Union (EU28), the proportion of recycling and, above all, energy recovery, are higher than the world average, at $39.4 \%$ and $29.7 \%$, respectively and landfilling is consequently lower. What is more significant is the growing importance of those treatments that, in 8 years, increased $46 \%$ and $64 \%$, respectively. This situation reflects the dominant position of this economic and political bloc in the environmental field, worldwide. Obviously, the situation differs from country to country, reflecting the different economic and social situation of each, and its specific legislative framework.

In Portugal, the document on waste, PERSU 2020 set targets that are in line with the various European Directives, transposed into national legislation [2]. The Landfills Directive is considered in these targets, which will increase the pressure on national agents to increase recycling of plastics and then their energy recovery [3]. In fact, this document assumes extremely ambitious targets for 2020, at the level of collection and referral for recycling of different materials and also at the packaging level.

\section{Railroad sleepers - Problems of wood}

The history of the railroad, in Portugal and in the world, is inseparable from the wooden sleepers. Over the course of more than 150 years of history since the birth of railways in Portugal, the applications of the wooden sleepers on the national rail network have continued to be extensive, whether in works of art, track sets or track sections in that it is not possible to change the track platform which allows the placement of a crosspiece in reinforced concrete, which is more sensitive to less robust track platforms.

In Portugal, the national rail network consists of about 2480 kilometers of roads open to the farm; of these, roughly 2145 kilometers are in the middle of concrete track and 254 kilometers in the middle of the wood track. The restriction on the placing of biocidal products on the market, introduced by Directive $98 / 8 / \mathrm{EC}$, has led to the initiation of a process of replacing several products traditionally produced in wood and requiring drastic treatment to withstand environmental aggressions. In this situation, for example, are electricity poles and wooden crossbars used on railway lines, which are subject to creosote treatments. The Community Directive 2011/71/ EU has imposed on the countries of the European Community an authorization registers for the use of this substance, creosote, which is still essential because there is no alternative for wood preservation. Recently the Execution Decision 2017/2334 of the Commission from 14 December 2017 extended the validity of the approval of creosote for use in biocidal products up to $31^{\text {st }}$ October 2020, meaning that there is an urgent need to substitute the wood sleeper for a tecno-environmental viable alternative.

In this context, the process of replacing wooden railway sleepers is at present a legal imposition which entails high costs and requires the existence of alternative sleepers produced in other materials and with the appropriate characteristics for the application.

The recycled plastic presents a great potential to replace the wood in the application, originating pieces with the required properties, as long as they are correctly conceived from the technical-scientific point of view. Sleepers made from recycled plastic have a list of advantages over other materials, such as: lower density, with great advantage in the application in bridges and overpasses; durability of plastics, without the need for harmful chemical treatments; do not absorb moisture and are resistant to microorganisms; its use 
avoids the slaughter of large numbers of trees for the production of sleepers; and finally, but of great importance, it significantly reduces the amount of waste mixed plastics deposited in landfill.

\section{Purpose}

This project intends to explore the possibility of producing a product, with high technical requirements and specific characteristics, from a mixture of plastics from the row of mixed plastics. The intention is to act in the level of valorization of this waste, to produce a product of high technical value - the crossings for railway lines. The final objective will be the development of eco-sustainable railway bridges (in the prototype phase), which will be tested in a real working environment.

Thus, starting from the technical and functional requirements of the sleepers, the project has the following specific objectives (which form the basis of the main research lines of this project):

- Research and development of a new material mainly of mixed plastics, where loads (long fibers) and nano loads will be introduced, which will increase its mechanical resistance and other characteristics such as electrostatic dissipation, among others;

- Investigation of a sleeper geometry (product specification) that allows answering functional assembly, damping and vibration issues. The geometry when combined with the material also plays a very important role in increasing the stiffness of the product;

- Investigation of a new production process that meets the requirements defined for this type of production. This new process should make it possible to increase the homogeneity of the material to be developed, mainly of PM, and to obtain railway crosspieces with more homogeneous sections at the material level. With the current production process, the products produced by Extruplás have empty spaces inside it, which has important implications for the decrease of the mechanical properties of the products produced and the overall variability of their properties. Parallel to the technical issues, the new production process will be evaluated from the environmental and energy point of view, and its sustainability compared to the process currently recommended in the company Extruplás;

- Development of Life Cycle Analysis and Cost, as well as the environmental evaluation of the sleepers tested in real scenario;

- Tests and tests of sleepers in real operating situation. 


\section{Consortium}

In order to carry out this project, a group of entities with experience and complementary skills, namely the leading company EXTRUPLÁS, the Innovation Pole in Polymer Engineering (PIEP) and the Center for Waste Valorization (CVR) which with the technical support of Infraestruturas de Portugal (IP) will be able to develop and test a new railroad of quality and with a lower environmental impact.

Overall the ECO SUSTAINABLE RAIL project will contribute to reduce the deposition of mixed plastics in landfill, respond to a need in the rail sector, as well as allow the expansion and differentiation of EXTRUPLÁS's product portfolio, which will strengthen its position in the recycling sector.

\section{Environmental Assessment - CVR ongoing work}

In EcoSustainable Rail project CVR is responsible for the environmental assessment of the new plastic sleeper and its comparison with traditional wood sleepers. Therefore, CVR will perform an environmental evaluation of the products as well as the LCA studies.

The ecotoxicological evaluation will be carried out in two phases and at different levels.

In the initial phase the product will be tested in two levels, being the first the sleepers composition (VOCs, Metals, PCBs, HAPs, etc) and its leaching (Metals, COvs, pH, etc).

In a second phase the environmental evaluation will involve the local where the new product will be installed, allowing to assess the impacts on the environment, namely soil (Metal, COVs, etc) and water (Metals, COVs, CQO, CBO5, etc). It is foreseen, to perform tests before and after the demonstration in real situation.

Regarding the LCA approach the main diagrams used in the EcosustainableRail projects are indicated in Figure 2, where it is shown the concept difference between wood and plastic sleepers. 


\section{Plastic Sleeper}

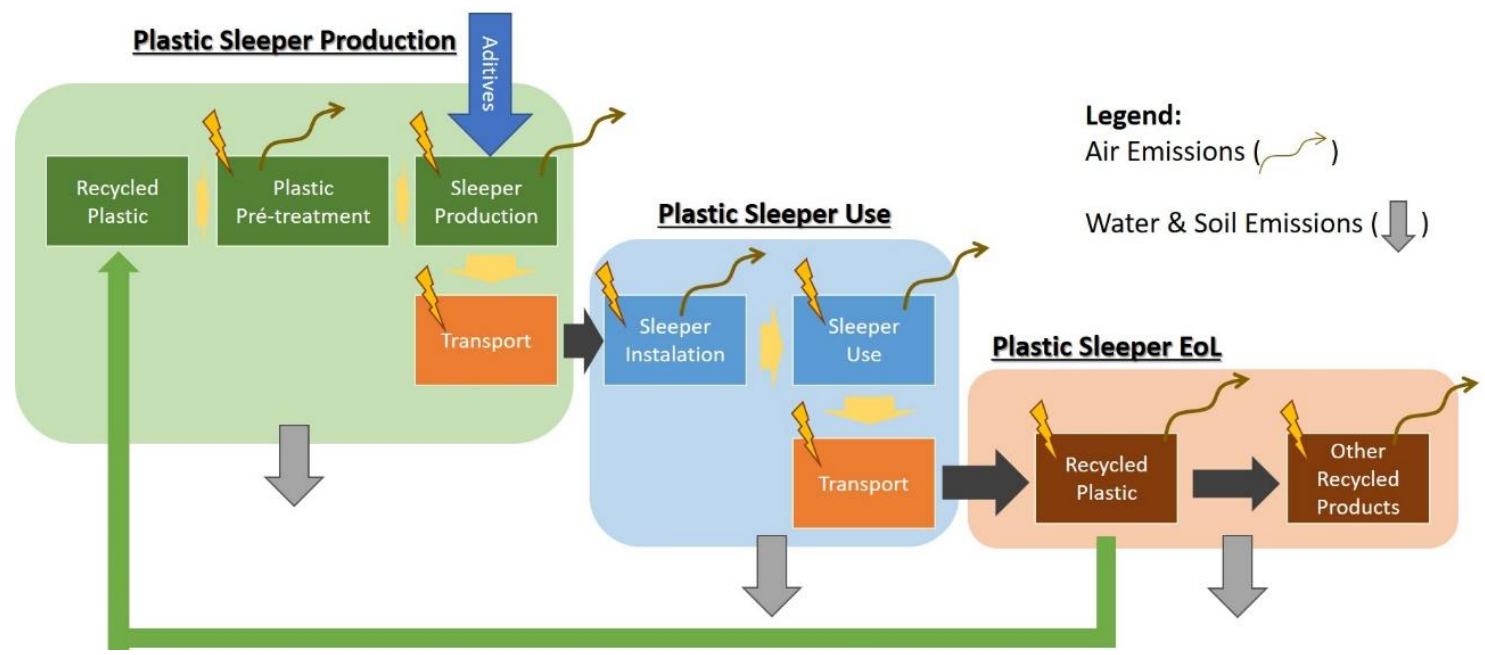

\section{Wood Sleeper}

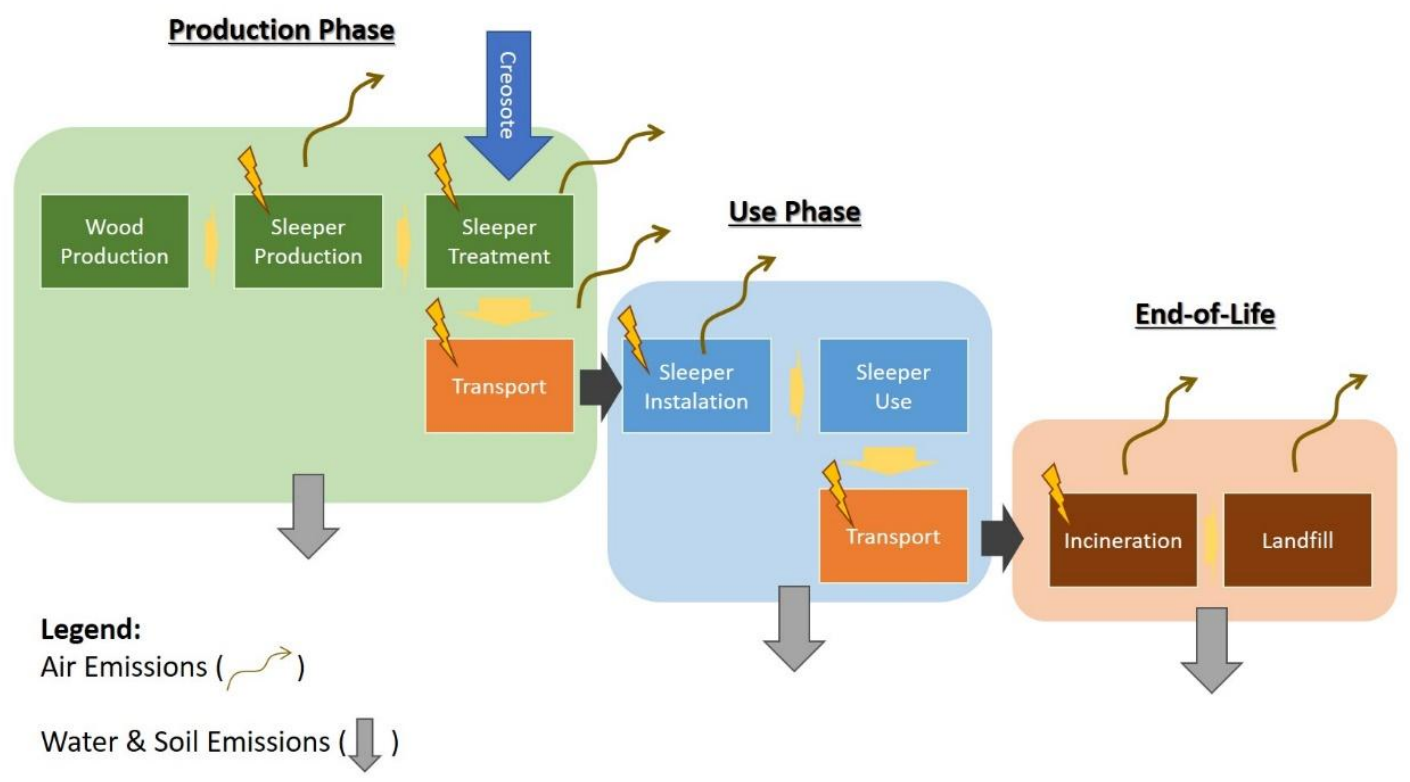

Figure 2. EcoSustainable Rail LCA approach 


\section{Aknowlegments}

This work has been co-financed by COMPETE 2020, Portugal 2020 and the European Union through the European Regional Development Fund (ERDF) under project POCI-01-0247-FEDER-017972, ECO SUSTAINABLE RAIL.

\section{References}

[1] Plastics. The Facts 2015, CONSULTIC \& Plastics Europe, European Plastics Converters, Brussels (2015).

[2] dIRECT No. 187-A / 2014, published in DR (Series I) No. 179, dated September 17, 2014, Urban Waste Strategic Plan (PERSU 2020). Ministry of Environment, Spatial Planning and Energy. 2014.

[3] Directive 1999/31 / EC of 26 April 1999 on waste landfill. Official Journal of the European Communities, L182 / 1. 1999.

[4] Directive 98/8 / EC of the European Parliament and of the Council of 16 February 1998 concerning the placing of biocidal products on the market.

[5] Commission Directive 2011/71 / EU of 26 July 2011 amending Directive 98/8 / EC of the European Parliament and of the Council to include creosote as an active substance in Annex I.

[6] Commission Decision (EU) 2017/2334 of 14 December 2017 extending the validity of the approval of creosote for use in biocidal products of type 8 . 